\title{
Relation between the iodine azide test and the TTCA test for exposure to carbon disulphide
}

\author{
J ROSIER, ' $\mathrm{G}$ BILLEMONT, ${ }^{2} \mathrm{C}$ VAN PETEGHEM, ${ }^{1} \mathrm{M}$ VANHOORNE, ${ }^{2} \mathrm{R}$ GROSJEAN, ${ }^{3}$ \\ AND A VAN DE WALLE
}

From the Laboratorium voor Bromatologie, ${ }^{1}$ Farmaceutisch Instituut, Rijksuniversiteit van Gent, 9000 Gent, Dienst voor Hygiene en Sociale Geneeskunde, ${ }^{2}$ Academisch ${ }^{\circ}$ Ziekenhuis, Rijksuniversiteit van Gent, 9000 Gent, and Laboratorium voor Industriele Toxicologie, ${ }^{3}$ Ministerie van Arbeid en Tewerkstelling, B-1040 Brussel, Belgium

ABSTRACT Exposure to carbon disulphide $\left(\mathrm{CS}_{2}\right)$ in a viscose plant was measured by personal monitoring and by application of the iodine azide test and quantification of 2thio-thiazolidine-4-carboxylic-acid (TTCA) in urine samples. A relation was found between the rise in urinary TTCA concentration during the workshift and the exposure index $E_{1}$. The correlation $(r)$ between the exposure index and the atmospheric concentrations of $\mathrm{CS}_{2}$ in workroom air below $100 \mathrm{mg} \mathrm{CS} / \mathrm{m}^{3}$ was $0.59(\mathrm{n}=9)$. The correlation between the increase in TTCA concentrations during the workshift and the atmospheric $\mathrm{CS}_{2}$ concentrations was found to be higher when urine samples at the end of the workshift with creatinine concentrations below $1 \mathrm{mg} / \mathrm{ml}$ and above $3 \mathrm{mg} / \mathrm{ml}$ were disregarded (from $\mathrm{r}=0 \cdot 61 ; \mathrm{n}=20$ to $\mathrm{r}=0 \cdot 84 ; \mathrm{n}=14$ ). A high correlation was found $(r=0 \cdot 86 ; n=13)$ when the end of workshift urine samples were analysed, provided that their creatinine concentrations are not beyond the limits given above.

The iodine azide test which is based on the fact that certain constituents in the urine of rabbits exposed to carbon disulphide catalyse the reaction between iodine and sodium azide, was developed by Vasak $e t$ $a l^{1}$ to evaluate the degree to which workers are exposed to carbon disulphide. The chemical reaction may be written as:

$$
2 \mathrm{NaN}_{3}+\mathrm{I}_{2} \rightarrow 3 \mathrm{~N}_{2}+2 \mathrm{NaI}
$$

The original method consisted of measuring the time needed for the disappearance of the yellowish brown colour of iodine on the addition of urine to the reaction medium. Vasak proposed an exposure index $\mathrm{E}$ in which

$\mathrm{E}=\mathrm{C} \log \mathrm{t}$

where $\mathrm{E}=$ exposure index, urine, and

$\mathrm{C}=$ creatinine concentration in $\mathrm{mg}$ per $\mathrm{ml}$

$\mathrm{t}=$ discoloration time in seconds.

Received 25 April 1983

Accepted 11 July 1983
The reaction between sodium azide and iodine proceeds slowly at room temperature but is apparently catalysed by the addition of a number of organic and inorganic compounds. This is thought to be due to the formation of an intermediary addition compound of the catalysing agent with iodine or sodium azide, which will then react with sodium azide or iodine respectively, forming nitrogen and iodide ions, and leaving the catalysing agents unchanged. ${ }^{2}$ The catalysing agents responsible for this reaction are most likely to be dithiocarbamate derivatives of amino acids and some other $\mathrm{CS}_{2}$ metabolites such as 2-mercaptothiazolinone- $5^{3}$ and thioureum ${ }^{4}$ which when added in pure form to the iodine azide solution, discolours it immediately. Some sulphur containing compounds derived from drugs or the diet, however, also catalyse the reaction, thus giving false positive results. In addition, the main disadvantage of the method is that discoloration occurs gradually, and there is no specific point of discoloration. Because of the subjective element in the readings, different exposure indices could be determined when the urine sample is added to the reaction mixture.

In 1981 Van Doorn discovered 2-thiothiazolidine-4-carboxylic-acid (TTCA) in the urine 
of workers occupationally exposed to $\mathrm{CS}_{2}{ }^{\mathrm{s}}$ TTCA is a heterocyclic five membered ring that is formed in the body by the reaction between carbon disulphide and glutathione. ${ }^{s}$ The quantification of TTCA in the urine of viscose workers thus seems to have interesting possibilities for the biological monitoring of $\mathrm{CS}_{2}$ exposure. ${ }^{6}$

\section{Materials and methods}

\section{PERSONAL MONITORING}

The concentration of $\mathrm{CS}_{2}$ in the workroom air was estimated over eight hours by means of personal monitoring pumps on workers from the different departments of a viscose plant (see Rosier $\mathrm{et} \mathrm{al}^{6}$ for further details.) From each group of shift and day workers ( 7 to 8 workers per group) two were asked to wear a personal monitoring pump, with the charcoal tube attached as closely as possible to the head in order to estimate the $\mathrm{CS}_{2}$ concentration in the breathing zone. The charcoal tubes were replaced after two hours, and sampling was carried out at periods of 120 to 360 minutes throughout the eight hour working period. $\mathrm{CS}_{2}$ concentrations were measured according to the NIOSH method SV $248^{7}$ as described elsewhere. ${ }^{\circ}$

\section{Biological monitoring}

\section{URINE SAMPLES}

The urine samples were collected at the beginning and at the end of the workshift and immediately deep frozen and stored at $-22^{\circ} \mathrm{C}$ until analysis.

Urine samples from the shift workers were taken during the last two days of a working period and at the beginning of a new period. In this way the TTCA concentrations obtained were directly related to the preceding exposure. After thawing, sediments were centrifuged off and the supernatant used for analysis.

\section{MODIFIED IODINE AZIDE TEST}

The test solution was prepared as prescribed by Djuric et al ${ }^{8}$ Discoloration in the solution was monitored using a photometer (Eppendorf) equipped with a $366 \mathrm{~nm}$ filter and carried out at a temperature of $23^{\circ} \mathrm{C}$; the discoloration time was measured as shown in fig 1 . The test was considered negative when discoloration did not occur within three hours and the exposure index was calculated as mentioned above.

\section{2-THIO-THIAZOLIDINE-4-CARBOXYLIC-ACID IN URINE}

Urinary 2-thio-thiazolidine-4-carboxylic-acid was determined according to the method of Van Doorn. ${ }^{9}$

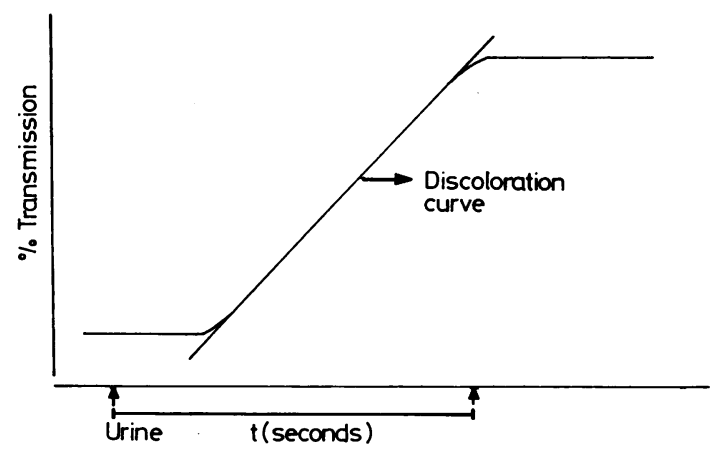

Fig 1 Discoloration curve of iodine azide reagent after adding urine of a worker exposed to carbon disulphide.

A high pressure liquid chromatograph (SpectraPhysics SP 8000) was used, equipped with a Hibar column $(25.0 \mathrm{~cm}$ long and $4.6 \mathrm{~mm}$ ID, packed with Lichrosorb RP-18/5) and a variable wavelength UV detector (Spectra Physics SP 8400) set at $273 \mathrm{~nm}$.

\section{CREATININE ASSAY}

The creatinine content of the urine samples was measured and analysed using a method based on the reaction of creatinine with alkaline picrate.

\section{SYNTHESIS OF}

2-THIO-THIAZOLIDINE-4-CARBOXYLIC-ACID

TTCA was synthesised according to the method of De Baun $e \mathrm{al}^{10}$ and purified by means of preparative high pressure liquid chromatography as described elsewhere."

\section{SYNTHESIS OF AMMONIUMGLYCINE \\ DITHIOCARBAMATE}

Ammoniumglycine dithiocarbamate was synthesised according to Jakubowski and Gessner as described elsewhere. ${ }^{12}$

\section{Results}

Table 1 shows the results of the iodine azide test and the concentrations of TTCA in the urine samples of the different workers together with their time weighted average (TWA) exposure values (in $\mathrm{mg} \mathrm{CS}_{2}$ per $\mathrm{m}^{3}$ of air) obtained by personal monitoring. As can be seen, the exposure to $\mathrm{CS}_{2}$ is high; only four workers have TWA exposure values below the TLV value for $\mathrm{CS}_{2}$ of $10 \mathrm{ppm} .^{12}{ }^{13} \mathrm{~A}$ description of their working conditions is given elsewhere. ${ }^{\circ}$

Figure 2 illustrates the relationship between the measured exposure indices (E) from end of workshift urine samples and the corresponding TWA exposure values $($ TWA exposure $=168-16 \cdot 7 \mathrm{E} ; \mathrm{r}$ 
Table 1 Carbon disulphide exposure. Iodine azide test and TTCA test on urine samples

\begin{tabular}{|c|c|c|c|c|c|c|c|c|c|}
\hline No & $T W A$ & $C$ & $t$ & $\log t$ & $E$ & $T T C A, b$ & TTCa, e & $T T C A, e(a)$ & $T T C A, i$ \\
\hline $\begin{array}{r}1 \\
2 \\
3 \\
4 \\
5 \\
6 \\
7 \\
8 \\
9 \\
10 \\
11 \\
12 \\
13 \\
14 \\
15 \\
16 \\
17 \\
18 \\
19 \\
20 \\
21\end{array}$ & $\begin{array}{r}69.6 \\
160.2 \\
96.6 \\
134.6 \\
136.9 \\
112.9 \\
80.3 \\
146.0 \\
89.4 \\
117.2 \\
144.2 \\
160.5 \\
28.4 \\
59.8 \\
41.2 \\
25.1 \\
39.3 \\
8.7 \\
31.5 \\
79.3 \\
15.2\end{array}$ & $\begin{array}{l}2.32 \\
2.32 \\
2.04 \\
0.96 \\
2.40 \\
2.36 \\
3.96 \\
2.44 \\
1.84 \\
0.96 \\
0.92 \\
0.52 \\
1.52 \\
1.24 \\
1.40 \\
2.44 \\
2.56 \\
2.96 \\
1.52 \\
0.38 \\
2.12\end{array}$ & 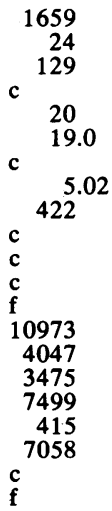 & $\begin{array}{l}3.22 \\
1.37 \\
2.11 \\
\text { c } \\
1.31 \\
1.28 \\
\text { c } \\
0.70 \\
2.62 \\
\text { c } \\
\text { c } \\
\text { c } \\
\text { f } \\
4.04 \\
3.61 \\
3.54 \\
3.87 \\
2.62 \\
3.85 \\
\text { c } \\
\text { f }\end{array}$ & $\begin{array}{l}7.47 \\
3.19 \\
4.31 \\
\text { c } \\
3.15 \\
3.02 \\
\text { c } \\
1.71 \\
4.83 \\
\text { c } \\
\text { c } \\
\text { c } \\
\text { f } \\
5.01 \\
5.05 \\
8.64 \\
9.92 \\
7.75 \\
5.85 \\
\text { c } \\
\text { f }\end{array}$ & $\begin{array}{l}1.8 \\
1.67 \\
2.97 \\
2.94 \\
0 \\
0.53 \\
2.52 \\
1.33 \\
1.55 \\
2.13 \\
2.37 \\
2.28 \\
0.50 \\
1.46 \\
0.72 \\
0.10 \\
0.10 \\
\text { d } \\
0.46 \\
0.32 \\
0.12\end{array}$ & $\begin{array}{r}3.71 \\
12.39 \\
15.79 \\
4.14 \\
8.12 \\
16.21 \\
13.6 \\
17.61 \\
10.78 \\
10.98 \\
7.37 \\
9.94 \\
3.38 \\
5.35 \\
2.32 \\
2.14 \\
2.37 \\
\text { d } \\
3.55 \\
4.88 \\
0.22\end{array}$ & $\begin{array}{r}7.62 \\
25.44 \\
28.51 \\
3.52 \\
17.25 \\
33.85 \\
47.66 \\
38.02 \\
17.55 \\
9.33 \\
6.00 \\
4.57 \\
4.55 \\
5.87 \\
2.87 \\
4.62 \\
5.37 \\
\text { d } \\
4.77 \\
1.64 \\
0.41\end{array}$ & $\begin{array}{r}1.91 \\
10.27 \\
12.82 \\
1.2 \\
8.12 \\
15.68 \\
11.08 \\
16.28 \\
9.23 \\
8.85 \\
5.00 \\
7.66 \\
2.88 \\
3.89 \\
1.60 \\
2.04 \\
2.27 \\
\text { d } \\
3.09 \\
4.56 \\
0.10\end{array}$ \\
\hline
\end{tabular}

TWA $=$ Time weighted average exposure value in $\mathrm{mg} \mathrm{CS} / \mathrm{m}^{3}$ of air.

$\mathrm{C}=$ Creatinine concentration in $\mathrm{mg}$ per $\mathrm{ml}$ urine.

$\mathrm{t}=$ Discoloration time in seconds.

$\mathrm{E}=$ Exposure index as defined by Vasak et al. . $^{\prime}$

TTCA $b=$ TTCA concentration in mmol TTCA per mol creatinine; beginning of workshift urine samples.

TTCA, e = TTCA concentration (same units) in end of workshift urine samples.

(a) = TTCA concentration in end of workshift urine samples in $10^{-5} \mathrm{mmol}$ TTCA per $\mathrm{ml}$ urine.

TTCA, $\mathrm{i}=$ Increase in TTCA concentration in mmol TTCA per mol creatinine.

$\mathrm{c}=$ Beyond creatinine limits set by Djuric et al.$^{\mathrm{s}}$

$\mathrm{d}=$ No beginning of workshift urine sample available.

$\mathrm{f}=$ Discoloration time greater than three hours.

$=-0 \cdot 82, n=14, p=0 \cdot 05)$. The exposure indices of the entire group of beginning of workshift urine samples were negative. There is no correlation between the exposure indices $E$ of the end of workshift urine samples and TWA exposure values $(r=0 \cdot 17$, $\mathrm{p}=0.05$ ) below $50 \mathrm{mg} \mathrm{CS}_{2}$ per $\mathrm{m}^{3}$ of air, but table 2 shows that the correlation increases in proportion to the degree to which the results of increasing levels of TWA exposure values are taken into account.

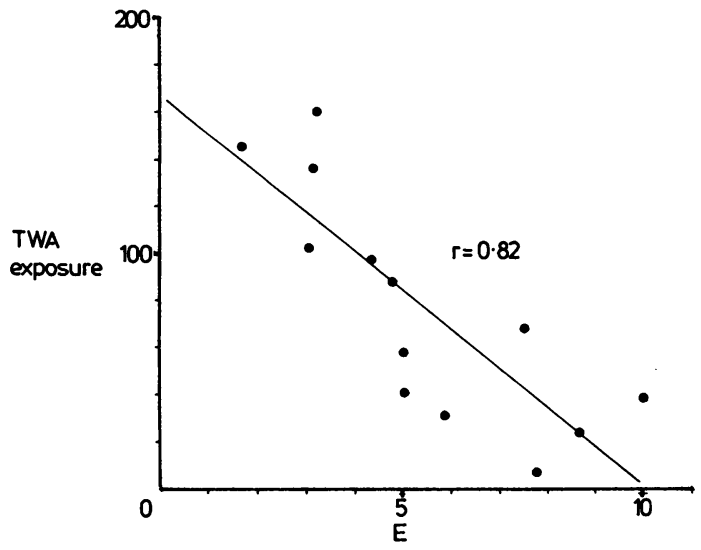

Fig 2 TWA exposure values (in $\mathrm{mg} \mathrm{CS}_{2} / \mathrm{m}^{3}$ of air) related to exposure index $E$ of end of workshift urine samples.
As may be seen in table 2 , even if the results at TWA exposure values lower than $100 \mathrm{mg} \mathrm{CS} / \mathrm{m}^{3}$ of air are taken into account, there is no clear correlation between $E$ values and TWA exposure values.

There is a clear correlation, however, between the urinary TTCA increments and the exposure index $(\mathrm{r}=-0.79, \mathrm{n}=12, \mathrm{p}=0.05)$. When TTCA results are related to the TWA exposure values a lower correlation is found than when the $E$ values are related to the TWA exposure values (fig 2) $(r=$

Table 2 Correlation coefficients ( $r$ ) for the exposure index $E$ and TWA exposure values at increasing levels of TWA exposure values

\begin{tabular}{lll}
\hline $\begin{array}{l}\text { TWA exposure lower } \\
\text { than: }\end{array}$ & $r$ & $n$ \\
\hline 41.2 & $0.18^{*}$ & 5 \\
59.8 & $0.46^{*}$ & 6 \\
69.6 & $0.29^{*}$ & 7 \\
89.4 & $0.48^{*}$ & 8 \\
96.6 & $0.60^{*}$ & 9 \\
112.9 & $0.72 \dagger$ & 10 \\
136.9 & $0.77 \dagger$ & 11 \\
146.6 & $0.83 \dagger$ & 12 \\
160.2 & $0.82 \dagger$ & 13 \\
\hline
\end{tabular}

TWA exposure values are given in $\mathrm{mg} \mathrm{CS} / \mathrm{m}^{3}$ of air.

$r=$ Correlation coefficient found between exposure index $E$ and TWA values.

$\mathrm{n}=$ Number of measurements.

$* \mathrm{p}>0.05$

$\dagger=p \leqslant 0.05$. 
$0 \cdot 61, \mathrm{n}=20$ to $\mathrm{r}=-0 \cdot 82, \mathrm{n}=13 ; \mathrm{p}=0 \cdot 05$ ). When the TTCA results with creatinine concentrations in end of workshift urine samples below $1 \mathrm{mg}$ creatinine per $\mathrm{ml}$ and above $3 \mathrm{mg}$ creatinine per $\mathrm{ml}$ are also disregarded, a much higher correlation is obtained $(r=0.84, n=14, p=0.05)$. If the increase in TTCA during the workshift is not considered, but only TTCA in the end of workshift urine samples, and only the results from the samples with creatinine concentrations above $1 \mathrm{mg}$ per $\mathrm{ml}$ and below $3 \mathrm{mg}$ per $\mathrm{ml}$ are accepted a high correlation is also obtained $(r=0.86, n=13, p=0.05)$ (fig 3$)$. Taking into account all the end of workshift urine samples without considering these creatinine limits, the $\mathrm{r}$-value decreases to $0 \cdot 35, \mathrm{n}=20$.

The relation between the concentration of TTCA ( $\mathrm{mmol}$ TTCA per $\mathrm{ml}$ urine) in end of workshift urine samples and the logarithm of their discoloration time is shown in fig $4 \mathrm{a}$ and indicates the effect of TTCA on the reaction rate between iodine and sodium azide. The correlation between the two is high, $\mathrm{r}=-0.92, \mathrm{n}=12, \mathrm{p}=0.05$. If pure TTCA is dissolved in water and appropriately diluted the discoloration times after adding iodine azide reagent given in fig $4 \mathrm{~b}$ are obtained. The concentration of TTCA in the pure solution is an exponential function of the disoloration time $\mathrm{t}$-that is, TTCA = $125,5 \mathrm{e}^{-0,033 \mathrm{t}}$, with $\mathrm{r}=0.85, \mathrm{n}=6, \mathrm{p}=0.05$. The question remains, however, as to whether or not the effect of the $\mathrm{CS}_{2}$ metabolites on the iodine azide reaction is purely catalytic. Ammoniumglycine dithiocarbamate, a possible metabolite of $\mathrm{CS}_{2}$ was traced by thin layer chromatography before and

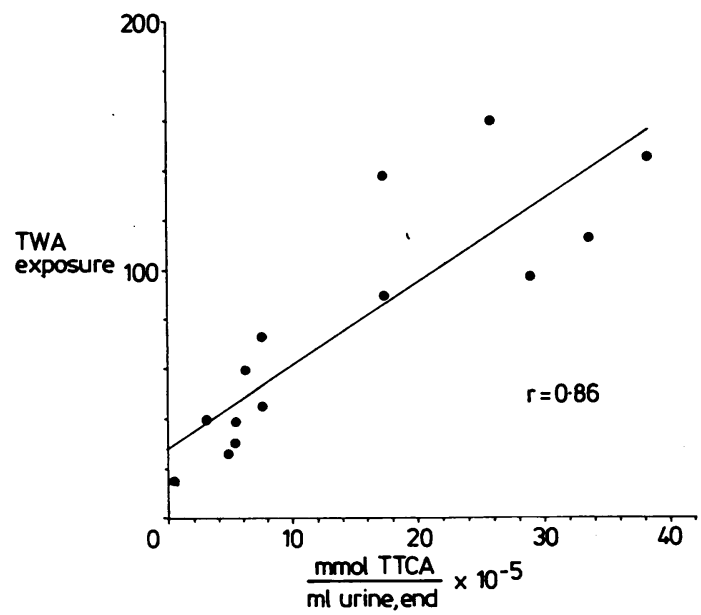

Fig 3 TWA exposure values related to concentration (mmol TTCA per $\mathrm{ml}$ ) in end of workshift urine samples with creatinine concentrations above $1 \mathrm{mg}$ creatinine per $\mathrm{ml}$ and below $3 \mathrm{mg}$ creatinine per $\mathrm{ml}$.

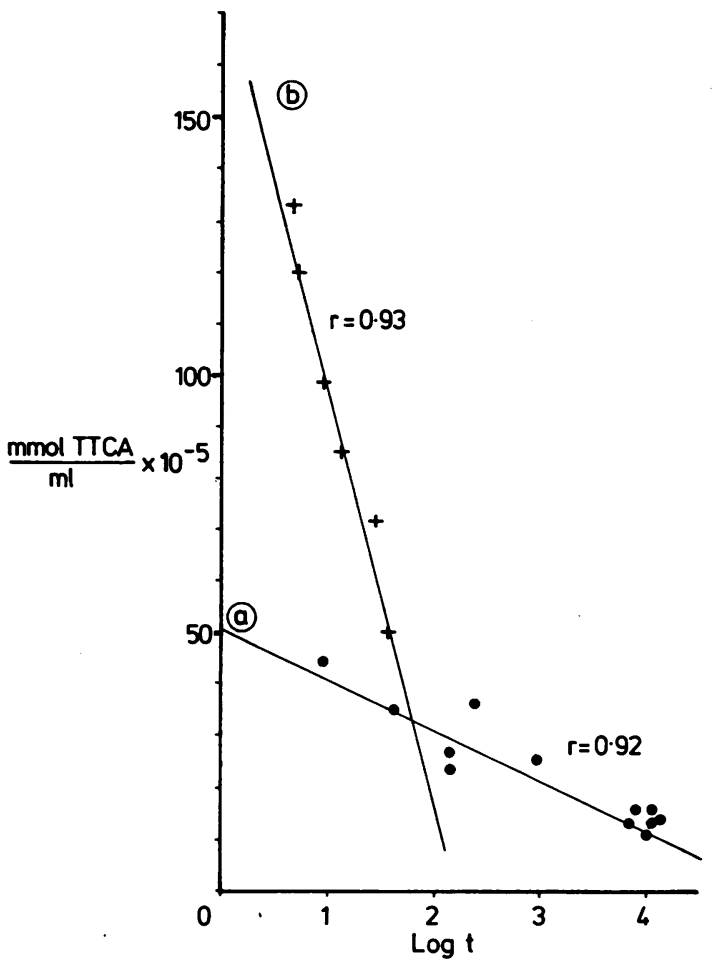

Fig 4 TTCA concentrations in urine (a) (mmol TTCA per $\mathrm{ml}$ ) and in water (b) related to the logarithm of the discoloration time after adding the iodine azide reagent.

after the iodine azide reaction. The compound was observed to disappear completely after the iodine azide reagent discoloured.

\section{Discussion}

There is a strong correlation between the exposure index E calculated according to Vasak's formula for the end of workshift urine samples and the increase in TTCA concentrations during the workshift. Table 2 indicates, however, that the limit of $50 \mathrm{mg} \mathrm{CS}$ per $\mathrm{m}^{3}$ of air which Djuric et al ${ }^{8}$ suggested as a threshold cannot be considered to be an absolute cut off point. The correlation between time weighted average atmospheric concentrations of $\mathrm{CS}_{2}$ obtained by personal monitoring and the increase in urinary TTCA concentration during the workshift can be improved by disregarding the end of workshift urine samples with creatinine concentrations below $1 \mathrm{mg}$ per $\mathrm{ml}$ urine and above $3 \mathrm{mg}$ per $\mathrm{ml}$ urine. It might have been expected that since the exposure indices $\mathrm{E}$ correlate strongly with the TWA exposure values and to the TTCA increments, that the latter would also correlate with the TWA exposure values. That they 
do not lies in the fact that the results used to relate the TTCA concentrations to the $E$ values were obtained solely from end of workshift urine samples with creatinine concentrations above $1 \mathrm{mg}$ per $\mathrm{ml}$ and below $3 \mathrm{mg}$ per $\mathrm{ml}$ urine. Figure 3 indicates that it is possible to collect only end of workshift urine samples to obtain a good estimate of the exposure to $\mathrm{CS}_{2}$.

The question as to whether or not the determination of TTCA in urine resulting from exposure to 50 $\mathrm{mg} \mathrm{CS} \mathrm{C}_{2}$ per $\mathrm{m}^{3}$ of air or even below $30 \mathrm{mg} \mathrm{CS}$ per $\mathrm{m}^{3}$ of air can be used to evaluate exposure to $\mathrm{CS}_{2}$ is still to be answered.

As shown in fig $4 \mathrm{~b}$, the concentration of TTCA in pure solution after adding iodine azide can be expressed by means of an exponential function, but the concentration of TTCA in urine cannot be expressed by a similar equation. Presumably, the other compounds responsible for the discoloration of the iodine azide reagent in urine have their own specific concentration-discoloration curves, which when added to each other result in a more complicated relationship. As may be seen from fig 4, for a given discoloration time, $(\log t=1$, for example) more TTCA is necessary in pure solution than in urine to induce the discoloration period, indicating the presence of other catalysing compounds.

It is clear from fig 4 that there is a specific TTCA concentration in urine and water with the same discoloration time. As the TTCA concentration increases, the decrease in discoloration time for the pure solution is not as great as the discoloration time for urine, indicating the presence of other compounds catalysing the iodine azide reaction stronger than TTCA. On the other hand, if the TTCA concentration decreases to $10 \mathrm{mmol}$ per $\mathrm{ml}$, it is obvious that the discoloration time will increase. This increase is greater for urine than for the pure solution indicating a more pronounced effect of the decrease of other compounds on the catalysis of the iodine azide reaction than TTCA.

This research was supported by the Fund for Medical Scientific Research under grant No 3.0013.81.
Requests for reprints to: J Rosier, Laboratorium voor Bromatologie, Farmaceutisch Instituut, Rijksuniversiteit van Gent, Harelbekestraat 72, 9000 Gent, Belgium.

\section{References}

' Vasak V, Venecek M, Kimmelova B. The assessment of the exposure of workers to carbon disulphide by the iodine azide test. Pracov Lek 1963;15:145-56.

${ }^{2}$ Feigl F. Spot tests. Vol 2. Organic applications. Amsterdam; Elsevier Publishing Company, 1954.

${ }^{3}$ Pergal M, Vukojevic N, Cirin-Popov D, Djuric D, Bojovic T. Carbon disulphide metabolites excreted in the urine of exposed workers. I. Isolation and identification of 2-mercapto-thiazolinone-5. Arch Environ Health 1972;25:38-41.

${ }^{4}$ Pergal M, Vukojevic N, Djuric D. Carbon disulphide metabolites excreted in the urine of exposed workers. II. Isolation and identification of thiocarbamide. Arch Environ Health 1972;25:42-4.

${ }^{5}$ Van Doorn R, Leijdekkers CM, Henderson P, Vanhoorne M, Vertin P. Determination of thio compounds in urine of workers exposed to carbon disulfide. Arch Environ Health 1981;36:289-97.

- Rosier J, Vanhoorne M, Grosjean R, Van De Walle E, Billemont G, Van Peteghem C. Preliminary evaluation of urinary 2-thiothiazolidine-4-carboxylic acid (TTCA) levels as a test for exposure to carbon disulfide. Int Arch Occup Environ Health 1982;51:159-67.

' National Institute for Occupational Safety and Health. Manual of analytical methods. Vol 2. 2nd ed. Cincinnati, Ohio: NIOSH, 1977.

${ }^{8}$ Djuric D, Surducki N, Berkes I. Iodine azide test on urine of persons exposed to carbon disulfide. $\mathrm{Br} J$ Ind Med 1965;22:321-33.

" Van Doorn R, Delbressine LPC, Leijdekkers CM, Vertin P, Henderson P. Identification and determination of TTCA in urine of workers exposed to carbon disulfide. Arch Toxicol 1981;47:51-8.

${ }^{10}$ De Baun JR, Miaullis JB, Knarr J, Mihailowski A, Menn JJ. The fate of $\mathrm{N}$-trichloro $\left({ }^{14} \mathrm{C}\right)$ methylthio-4-cyclohexene-1. 2-dicarboxiimide $\left({ }^{14} \mathrm{C}\right.$-captan) in the rat. Xenobiotica 1974;4:101-19.

" Rosier J, Simonds R, Van Peteghem C, Vanhoorne M. The preparation of pure 2-thio-thiazolidine-4-carboxylic-acid (TTCA as a reference standard for carbon disulfide exposure tests Bulletin des Societes Chimiques Belges 1983;92:397-402.

12 Jakubowksi M, Gessner T. S-Methylation of dithiocarbamate derived from amino acids. Biochem Pharmaco 1972:21:3073-6.

${ }^{13}$ National Institute for Occupational Safety and Health. Summar of NIOSH recommendations for occupational health standards Washington DC: US Department of Health and Human Ser vices, 1980.

${ }^{14}$ TLV Airborne Contaminants Committee. Threshold limit value for chemical substances in workroom air adopted by the Ameri can Conference of Governmental Industrial Hygienists, Cincin nati. Cincinnati: ACGIH, 1981. 